\title{
LA ESCUELA VISTA POR MUJERES \\ DE TRES GENERACIONES DE MÉXICO Y COLOMBIA
}

\author{
SCHOOL AS SEEN BY WOMEN OF THREE DIFFERENT \\ GENERATIONS FROM MEXICO AND COLOMBIA
}

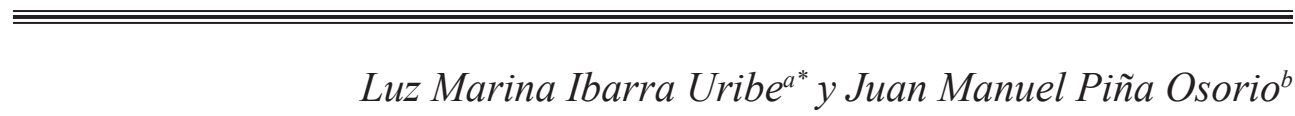

Fechas de recepción y aceptación: 15 de marzo de 2018, 24 de octubre de 2018

Resumen: El artículo presenta hallazgos de una investigación sobre la percepción que de la escuela, su función y quehacer tienen triadas familiares de hombres y mujeres de dos países latinoamericanos. Para este trabajo se seleccionaron dos triadas de mujeres (abuelas, madres y nietas), una colombiana y otra mexicana, con el objetivo de recuperar, a través de narrativas, lo que representó y representa para ellas y sus familias su paso por la escuela; así como identificar las continuidades, cambios y rupturas experimentadas por dichas generaciones. Uno de los hallazgos importantes es la relevancia que le confieren al hecho de haber estudiado en escuelas privadas de corte confesional católico, por la oportunidad de aprender y formarse dentro de valores, hábitos y disciplinas que resultan tanto o más importantes en su formación que los propios conocimientos disciplinares. Se encontraron en los relatos sentimientos positivos respecto a los logros educativos personales y de la familia. Asomaron en los testimonios emociones como orgullo, satisfacción y alegría por asistir a la escuela, y en el caso de las mujeres que no concluyeron sus estudios, arrepentimiento y frustración.

Palabras clave: escuela, educación, generación-familia.

a Facultad de Estudios Superiores de Cuautla. Universidad Autónoma del Estado de Morelos.

${ }^{*}$ Correspondencia: Universidad Autónoma del Estado de Morelos. Facultad de Estudios Superiores de Cuautla. Carretera México-Oaxaca N. ${ }^{\circ}$ 218. Colonia Plan de Ayala, H.H. 62743 Cuautla. Morelos. México.

E-mail: marina.ibarra@uaem.mx

${ }^{\mathrm{b}}$ Instituto de Investigaciones Sobre la Universidad y la Educación (IISUE). Universidad Nacional Autónoma de México. 
Abstract: This article presents findings about the perception of school, its function and purpose according to family triads of men and women from two Latin American countries. For this work, we used two triads of women (grandmothers, mothers and granddaughters), one of them Colombian and the other Mexican, with the purpose of discovering, through their narrative, what their time at school represented and still represents for them, while also identifying continuities, changes and ruptures experimented by the aforementioned generations. One of the most important findings is the worth they give to the fact of having studied in private Catholic schools, and to the opportunity of learning and having an education in values, habits and discipline, three elements which are just as important or even more important for their education than the academic contents themselves. In their findings, we found positive feelings regarding their individual and family educational achievements. We also found feelings of pride, satisfaction and joy for having gone to school, and in the case of the women who didn't finish their studies, regret and frustration.

Keywords: school, education, generation-family.

\section{INTRODUCCIÓN}

Históricamente, la escuela ha sido vista como la institución que alberga la herencia cultural de una sociedad, tanto por los conocimientos impartidos a los educandos como por su formación moral, cívica y preparación para la vida adulta. Es finalmente un espacio de tránsito entre la familia, la sociedad y el mundo adulto, el mundo del trabajo. No obstante, para algunos autores lleva tiempo sumida en una crisis de valores. Vasen advierte: "antes, la escuela era la principal fuente de saberes extra-familiares; aquel templo del saber se ha convertido casi casi... en una empresa como otras que provee habilidades y opiniones para su venta en el mercado laboral" (2008: 84).

Sin embargo, la permanencia de esta institución y su legitimidad actual la mantienen vigente. Cada generación la ha percibido y asumido de manera diferente en función de sus necesidades y circunstancias. En esta empresa, la familia, en particular la mujer, ha jugado un papel importante para mantener esa fe en la escuela, en sus propósitos, su misión, visión y utopías. Sin duda, ese vínculo escuela-familia ha contribuido a enfrentar y contener la adversidad, la desesperanza y la incertidumbre contemporánea. 
El presente artículo $^{1}$ tiene dos objetivos: $a$ ) la percepción que de la escuela, su función y quehacer, tienen triadas familiares de mujeres (abuelas, madres y nietas; una colombiana y otra mexicana); y $b$ ) identificar las permanencias, cambios y rupturas experimentadas por dichas generaciones, así como la trascendencia de la formación escolar en su vida.

En la primera parte de la exposición se definen los conceptos escuela y generación-familia. Posteriormente se presenta la metodología y las técnicas empleadas en esta investigación. Se continúa con la comparación que hacen las mujeres participantes con respecto a la función social de la institución educativa y su marcada preferencia por la educación privada. Se cierra con algunas reflexiones.

\section{IMPORTANCIA SOCIAL DE LA ESCUELA}

Podemos afirmar que es una institución producto de una construcción social, cultural y económica. Es un fenómeno histórico, más allá de que se piense como una entidad eterna, y por tanto natural y universal. No obstante, su conservadurismo institucional ha cambiado y logrado adaptarse a las nuevas exigencias; permaneciendo como una institución insustituible e irrenunciable. Resulta inconcebible pensar la formación de los sujetos sin su existencia.

Su origen se remonta al mundo antiguo. En su versión actual, es hija de la modernidad, surgida en el siglo XVIII (Vázquez, Sarramona, y Touriñán, 2009). Nació para instruir y capacitar, pero actualmente la han vuelto una entidad cada vez más compleja, por las tareas, alcances y expectativas que se le atribuyen. Los resultados esperados se quedan muy por detrás de lo deseable, exigiéndole e incluso culpándola de manera injusta y desproporcionada de muchos de los problemas sociales, económicos y culturales que aquejan a nuestras sociedades. Su función consiste en establecer una mediación entre los sujetos y la cultura de la sociedad a la que pertenece, con miras a proporcionarle a las nuevas

\footnotetext{
${ }^{1}$ El artículo se elaboró en una Estancia de Investigación en el Instituto de Investigaciones Sobre la Universidad y la Educación (IISUE), de la Universidad Nacional Autónoma de México (UNAM), auspiciada por el Programa para el Desarrollo Profesional Docente (PRODEP) de la Secretaría de Educación Pública de México (septiembre 2017-febrero 2018).
} 
generaciones un desarrollo particular, acorde con los valores y aspiraciones que dominan socialmente.

La escuela representa -después del hogar y de la primera infancia- el espacio por antonomasia para garantizar la correa de transmisión cultural y de socialización de una generación a la otra. Se encarga de continuar con la tarea iniciada desde el nacimiento del sujeto hasta sus primeros años de vida. Esta transferencia es permanente y acumulativa. Por la legitimidad y expectativas que despierta en los adultos, es el instrumento de socialización más efectivo y eficiente para preparar el relevo generacional, conservar y acrecentar los valores, alcanzar la movilidad social y económica. Es además la institución más eficaz de que dispone el Estado para la reproducción social.

A través de su funcionamiento logra imponer, como lo afirma Pérez (2000: 11), "lentamente pero de manera tenaz, unos modos de conducta, pensamiento y relaciones propios de la institución que se reproduce a sí misma, con independencia de los cambios radicales que se provocan en su entorno". Varios autores han coincidido en afirmar que entre las instituciones sociales que más lentamente cambian o se adaptan al ritmo de las transformaciones sociales, son el ejército, la iglesia y la escuela.

Gvirtz, Grinberg y Abregú (2012) afirman que con diferentes nombres, formatos y costumbres, esta institución está inmersa en objetos, espacios y prácticas comunes a todos, aunque, en otro tiempo y lugar hayan existido modelos y prácticas diferentes a los actuales. Para estas autoras, más allá de la generación a la que pertenecemos, siempre reconocemos un edificio con su dirección, salones contiguos, patios, bibliotecas, sanitarios colectivos, revisiones de higiene, cooperativa, un timbre o campana, uniformes, escudos, distintivos, un asta bandera y el acto cívico, formaciones y marchas militares, mochilas, libros, lápices, colores, cuadernos, reglas, carpetas, pupitres, pizarrones, dictados, premios, castigos, reconocimientos y estigmas.

Para Carbonell (1996) -muy en la línea de Dewey- la escuela posee dos componentes irrenunciables. Por una parte, el cultural: bastión de los conocimientos y también de las aspiraciones, prácticas y cosmovisión de cada sociedad, para legarlo a los jóvenes y garantizar con ello la conservación de un determinado patrimonio sociocultural. Por la otra, el componente educativo, orientado a la inculcación de ciertos valores, normas, hábitos y actitudes, lo que hemos conocido como la educación moral y cívica. 
Según el espacio geográfico, el tiempo y la posición de clase social a la que se pertenece, la institución educativa cubre una serie de funciones sociales adicionales que le dan razón y sentido a su existencia: transmisión de información, capacitación y formación de los sujetos sociales. Para Gvirtz, Grinberg y Abregú (2012), además distribuye conocimiento, transmite valores, forma ciudadanos, capacita para el trabajo y contribuye al desarrollo de la sociedad. En tanto que para Carbonell (1996), esas funciones sociales se ven incrementadas con: “... el consenso ideológico, el control social para garantizar la ley, el orden y la paz; la reproducción del orden social existente mediante la selección escolar y la función de custodia y contención" (1996: 33). Podría agregarse al listado anterior la formación de una conciencia nacional, el adoctrinamiento religioso o político a su población al disciplinarla, imponerle hábitos, promover su socialización e interacción con sus pares.

Es un espacio altamente valorado por los adolescentes como sitio de encuentro y convivencia. Cuanto mayor cantidad de años de escolaridad, esta puede llegar a dispensar estatus, orgullo de pertenencia y oportunidad de privilegio. Sin lugar a dudas la escuela es una institución multifuncional. Al hablar de su importancia Fingermann explica:

[...] Es además un lugar donde se aprende a compartir, y donde nacen lazos afectivos que en muchas ocasiones acompañan durante toda la vida. En nuestra sociedad liberal, democrática y capitalista, es un medio, a veces el único, que posibilita el ascenso social. [...] La escuela forma para seguir estudiando, para trabajar en mejores condiciones, y fundamentalmente, para la vida (2011).

En el pasado, como en la actualidad, para los padres es normal que sus hijos estudien, aunque complicado de lograr en la medida en que van incrementándose los años de escolaridad. Sin embargo, difícilmente tienen en mente otra opción viable de formación y movilidad socioeconómica para la realización de sus hijos. Su asistencia a la escuela representa la posibilidad de tener una vida diferente a la que ellos tuvieron, o como es frecuente escuchar, proporcionarles en vida una herencia que nadie les arrebatará. Puede coadyuvar para alcanzar la independencia y, en la educación superior, llega a funcionar incluso, como espacio para encontrar pareja. 
De acuerdo con Saucedo (2003), dentro de los estudios sobre la escuela, se distinguen dos tendencias de investigación: una, que podríamos denominar de corte determinista, y la otra, que engloba estudios cualitativos o de corte cultural. En los estudios de corte determinista se presenta a la familia y a sus hijos condicionados por su situación material y cultural, y casi siempre con escasas posibilidades de alcanzar un impacto favorable de la escuela y de su formación escolar.

Desde una visión distinta, añade Saucedo, los estudios culturales reconocen las condiciones históricas, materiales y socioculturales en las que se construyen formas de relación con dicha institución. Estas posturas no pierden de vista que existen choques culturales entre las familias y la escuela, que hay prácticas de discriminación y exclusión escolar o relaciones de poder y control. Sin embargo, los padres y sus hijos son agentes activos, que reivindican su historia como grupo y que perciben sus condiciones materiales y económicas de modo distinto.

El presente artículo se inserta en una tónica analítica similar. El propósito es entender y recuperar la percepción y relevancia que tuvo (o tiene) en la vida familiar de mujeres de tres generaciones (una mexicana y otra colombiana), su paso por una institución educativa en particular. El documento parte de una investigación más amplia donde también se entrevistaron a generaciones de varones de ambos países. Se quiere indagar en la manera en que perciben la escuela como institución para contener la adversidad, la desilusión y la falta de certidumbre que ha generado la violencia y el rezago social y económico en estos dos países.

Un hallazgo interesante es la relevancia e importancia que le confieren las mujeres al hecho de haber estudiado en colegios privados de corte confesional católico, donde aprendieron, además de conocimientos, valores, hábitos y creencias que han conservado y transmitido de una generación a otra. En los relatos también aparecen sentimientos positivos respecto a los logros educativos o su contribución para que otros integrantes de la familia realicen estudios. Emociones como orgullo, satisfacción, alegría, interés, gusto y entusiasmo son las más recurrentes. En el caso de las que no concluyeron su formación escolarizada, manifiestan arrepentimiento y frustración por ello y valoran positivamente la educación. 


\section{GENERACIÓN-FAMILIA}

De acuerdo con Martín (2009), el concepto de generación responde a varios significados. Se puede asumir como cohorte de nacimientos, como grupo etario, como conjunto de sujetos con un rasgo identitario o, para señalar alguna relación de parentesco, como "los abuelos de hoy", los "hijos de la generación multimedia", etc. En la actualidad, gracias al aumento de la esperanza de vida, pueden llegar a coexistir en una familia hasta cuatro generaciones. Esto permite hablar de familias multigeneracionales, lo cual alude a la diversidad o coexistencia de varias generaciones, mientras que lo intergeneracional enfatiza la interacción entre ellas.

Para Donati (1999), el concepto se ha visto alterado históricamente, de manera que ahora existen jóvenes informados sobre el tema que asumen ser una no-generación. Esto ha llevado a repensar cómo se configura una generación y a pensar en generaciones, sobre todo a relacionar el término con otras instituciones, como sería el caso de la familia. Sugiere abordarlo de la siguiente manera:

La generación es el conjunto de personas que comparte una relación, aquella que liga su colocación en la descendencia propia de la esfera familiar-parental (esto es: hijo, padre, abuelo, etc.) con la posición definida en la esfera social (es decir: de acuerdo con los grupos de edad: jóvenes, adultos, ancianos, etc.). Debemos hablar de hijos jóvenes, hijos adultos, de hijos ancianos, lo mismo que de padres jóvenes, padres adultos, de padres ancianos. Debemos hablar de abuelos jóvenes, abuelos adultos, de abuelos ancianos. Estas son las "nuevas generaciones" que se esconden detrás del "complicado entramado" de generaciones que ha sido creado por nuestra sociedad por primera vez en la historia (1999: 37).

En consecuencia, la generación es una relación y no una etapa cronológica. Privilegia el enlace entre descendencia familiar y edad social, y no una unidad histórica o exclusivamente como grupo de descendencia. De acuerdo con Donati, una generación, en sentido sociológico, combina la edad histórica con la relación de descendencia. "No basta una u otra. Es ahí, en su nexo, que yace el sentido sociológico de esa generación" (1999: 37). En otras palabras: 
Con el concepto de generación ligado al de familia se parte de la idea de que cada generación se forma a través de ciertas categorías culturales del momento de acuerdo con un contexto histórico y a la vez arrastra las expectativas de generaciones anteriores, la trayectoria familiar (Caballero, 2014: 58).

\section{Metodología}

La investigación fue de corte narrativo. Se llevó a cabo por medio de relatos de vida. En el sentido de Bernasconi:

Los estudios narrativos no se restringen a un conjunto de métodos de investigación, un número de técnicas de análisis o una serie de procedimientos para verificar resultados. Son, básicamente, una forma de indagación sobre la práctica narrativa y los relatos que personas, grupos e instituciones componen en y sobre la vida social.

El enfoque surge de la constatación de dos hechos fundamentales. Primero, reconoce que una forma básica a través de la cual los seres humanos otorgan sentido a sus experiencias es pensándolas como historias o relatos. Segundo, constata que la práctica de contar historias (o la narrativización) constituye una forma de comunicación humana fundamental (2011: 13-14).

Los relatos de vida según Saucedo (2003) "proporcionan información sobre la manera en que las personas organizan sus recuerdos, utilizan modelos culturales para enmarcar sus experiencias de vida o reconstruyen el significado y valor de las cosas, por ejemplo de la escuela" (2003: 82). Y advierte sobre la necesidad de trabajar con los contextos en los que transcurre la vida de las personas que narran sus experiencias.

En el caso de este trabajo, los relatos orales fueron recogidos a partir de entrevistas semiestructuradas. Se elaboraron dos guiones, uno para las abuelas y las madres y otro para las nietas. El primero estaba dividido en cinco partes: familia de origen, la vida en la escuela (juegos, castigo, violencia), importancia de la educación escolarizada, educación pública vs. educación privada y la familia que formaron. El guion para las nietas omitía este último apartado, porque la mayoría son solteras. En el artículo se consideran algunos 
hallazgos relativos a la importancia de la escuela y las instituciones donde cursaron sus estudios.

Para esta contribución se seleccionaron solo dos triadas (abuela, madre y nieta mexicanas de la misma familia, y abuela, madre y nieta colombianas igualmente emparentadas); sus edades oscilan entre los 84 y 35 años. Todas, excepto una abuela, estudiaron en colegios privados de órdenes religiosas. En sus narrativas se entretejen historias de la familia y la escuela. Pero a su vez cada abuela, madre y nieta construyó su propia historia, dando sentido y significado. Externaron sentimientos, emociones y percepciones, "con los referentes de su época y desde la perspectiva del ciclo vital en que se encontraba" (Bernasconi, 2011: 11).

En sus relatos convergió la temporalidad del individuo, de la generación, de la escuela y de la familia. Dejaron de manifiesto el papel que han desempeñado las mujeres para que los integrantes de su familia pudieran o puedan asistir a la escuela, no obstante las limitaciones económicas y las creencias de la época que las excluían o minimizaba la importancia para que estudiaran.

Las características consideradas para la selección de las informantes se basaron en el "muestreo teórico por conveniencia", ya que se seleccionaron de acuerdo a criterios determinados para esta investigación. En el texto se analizan relatos de vida (fragmentos) de dos triadas consideradas típicas ${ }^{2}$, es decir, representativas de otros casos sin pretensión alguna de establecer generalizaciones; tal y como lo diría Stake, "el objetivo primordial del estudio de un caso no es la comprensión de otros. La primera obligación es comprender este caso" (2010: 17).

Según Bertaux, "una de las condiciones para que un relato de vida se desarrolle plenamente es que el interlocutor desee contar su vida y que se adueñe de la conducción de la conversación" (1999: 10). En este caso, las seis entrevistadas aceptaron expresar voluntariamente sus opiniones, emociones, sentimientos, vivencias y significados.

${ }^{2}$ Entre agosto de 2017 y abril de 2018, se entrevistaron a treinta personas en Colombia y México, distribuidas en diez triadas, cuatro de hombres y seis de mujeres. 
El procedimiento para realizar el trabajo de campo ${ }^{3}$ incluyó la visita a sus hogares, la mayoría en un solo encuentro, aunque en algunos casos la entrevista requirió de dos sesiones (se pidió autorización verbal para grabar). La información recabada fue transcrita con detalle. Se codificaron los datos para dar inicio a una primera fase: la construcción de los relatos de vida de cada familia, para dar voz a los actores sociales. Al mismo tiempo se realizó el análisis con el programa Atlas ti, que fue el eje principal para identificar continuidades, permanencias y rupturas en la percepción de la escuela y la educación escolarizada que expresaron las dos triadas.

Las mujeres entrevistadas pertenecen a sectores de clase media. Se desempeñan en el sector comercial y en los servicios. En cinco familias, la manutención del hogar ha sido compartida entre ellas y sus parejas. Las abuelas y las madres no son nativas del lugar donde se asentaron y procrearon su descendencia; llegaron provenientes del medio rural a ciudades pequeñas en proceso de crecimiento (medio urbano), en busca de mejores condiciones materiales de vida. Las abuelas provienen de familias de once y diecisiete miembros y las de las hijas están conformadas por padre, madre y tres hijos. Todas cursaron al menos la educación primaria, incluso algunas alcanzaron la máxima escolaridad de su tiempo y del lugar donde radicaban. Un dato adicional importante es que todas se consideran como católicas.

\section{COMPARACIÓN GENERACIONAL: LA FUNCIÓN SOCIAL DE LA ESCUELA}

Las mujeres participantes expresaron su satisfacción por haber asistido a la escuela, al igual que sus hijos. Destacan la importancia de que estos se educaran y alcanzaran movilidad social, la cual difícilmente hubieran conseguido sin la escolarización. Aunque sobresale la idea de que el estudio permite ob-

${ }^{3}$ El trabajo de campo se realizó en Medellín, Antioquia, Colombia y Cuautla, Morelos, México. Se seleccionaron estos contextos geográficos por su similitud en relación con la violencia, debida a la operación y combate al crimen organizado. La intención fue conocer hasta qué punto una situación como la vivida en Medellín y la que enfrenta Cuautla tienen algún impacto en la percepción de los sujetos para asistir a la escuela, ante la presión y la tentación a que se ve sometida la población joven de incorporarse a actividades ilícitas. 
tener un mejor empleo "para poder comprarse lo que uno quiera", hay otros argumentos: "tomar mejores decisiones, saber hablar, poder desarrollarse en diferentes espacios geográficos y culturales, seguir aprendiendo, capacitándose, ser capaces de tener solvencia económica, levantar y formar una familia, ser respetado, poseer conocimientos, valores y hasta para escapar de los problemas de diferente tipo". A modo de ilustración se presentan algunos relatos de la triada mexicana:

Abuela:

Pues le decían a uno que el estudio servía para que fueran mejores, al menos era mi interés principal. Antes de casarme yo siempre dije "yo no voy a tener más de dos hijos, cuando mucho tres, para que estudien todos, lo que yo no fui tienen que ser ellos". Yo sabía que no sabía nada para ayudarles, pero yo dije que tenían que estudiar.

Yo les decía: "tienen que estudiar hijos porque mírenme a mí, trabajo mucho porque no tengo un título, un trabajo que valga la pena, yo tengo que ver cómo le hago para ustedes, pero me tienen que responder, [...] yo no quiero que se queden como yo, ni como tu papá". Porque mi marido solo hizo secundaria porque se fue a trabajar.

Uy pues sí, [estudiar sirve para tener] un buen empleo, matándose menos, y como que hasta la gente te respeta más, yo siento, porque entre más estudias pues más eres. Será tontería, pero yo siento que sí vale mucho (Abuela-Méx.).

\section{Madre:}

Porque uno tiene que ir [a la escuela], o sea uno tiene que ir porque uno necesita de los conocimientos más básicos, ya si no quieres estudiar después pues es tu bronca, pero sí, buenos modales, bueno al menos ahí nos daban clases de buenos modales también. Entonces son cosas que vas a aplicar siempre. Y nos enseñaban a ser responsables (Madre-Méx.).

Nieta:

O sea, sí fue importante para mí ese tiempo [de ir a la escuela], no fue así como que lo más importante, pero era [...] como que mi distracción, entonces sí me ayudaba mucho la escuela, mis amigas, para pasar todas esas cuestiones de mi 
familia, de esos problemas de casa, era así como que mi escape. Y cuando me iba con las amigas, que salíamos los viernes, era mi distracción.

Yo creo por eso soy tan exigente con ellas [mis hijas], porque no quiero que cometan el mismo error que yo, entonces sí les exijo a las dos todo y me haces la tarea y no te paras hasta que no termines. Como yo no tuve tanta [atención], [...] sí me hubiera gustado que me pusieran más como [atención], que fueran un poquito más estrictos mi papá o mi mamá.

Todas [las etapas son importantes] desde primaria hasta universidad, yo creo que es como que tu formación que define qué vas a ser, obviamente si terminas tu carrera tienes más posibilidad de encontrar un trabajo, si eres competente un buen trabajo, ganar un mejor sueldo. Conocer pues el mundo, hay trabajos donde te mandan de aquí, para allá, el que está más preparado tiene más posibilidades de salir adelante [...] para tener mejores oportunidades es primordial.

Así como va [le dice a su hija mayor], "tienes que estudiar si quieres superarte"; a ella le encanta gastar, "cuando te gusta gastar, quieres ir de vacaciones, ahorita tus papás no te lo pueden dar, tú estudia mucho échale ganas para que cuando ya estés grande te puedas pagar todo lo que tú quieras" (Nieta-Méx.).

A pesar de que la abuela mexicana dijo que para ella hubiera sido un gran orgullo que todos sus hijos terminaran al menos la licenciatura (educación terciaria), una no quiso seguir estudiando, cursó la secundaria y entró en una carrera técnica, sus expectativas eran concluir y trabajar en una institución bancaria. Señala que su escuela contaba con un convenio para hacer las prácticas profesionales allí e incluso algunas jóvenes después se quedaban a trabajar de cajeras. Sin embargo, cuando le faltaba muy poco para terminar su carrera, se embarazó y nunca concluyó su formación escolarizada. En realidad, la hija había elaborado un deseo diferente al de su mamá, ella quería estudiar poco, trabajar y pronto tener su propio dinero. La nieta de esta triada tampoco evaluó en sentido negativo la escuela, a pesar de que no concluyó el bachillerato, de hecho dice estar arrepentida y se esfuerza por que "sus hijas no comentan el mismo error"; simplemente no logró acreditar una de las asignaturas (matemáticas).

Empero las fuertes críticas al enfoque funcionalista que privilegia la formación educativa como medio para obtener y desempeñar un empleo en el mercado laboral, las triadas entrevistadas, en lo general, aseguran que si han 
mejorado sus condiciones de vida ha sido gracias a su escolaridad. Están convencidas de que estudiar da mayores posibilidades en la vida; dejan ver en sus relatos el gran valor que confieren a la educación, hablan de ella en positivo. Esto se ha trasmitido de manera intergeneracional.

Las madres remembraron su preocupación en el momento de elegir y poder solventar los gastos de la formación escolarizada de sus hijos/as y, posteriormente, estar en condiciones de apoyarlos en la elaboración de sus deberes. Por una parte, el costo de las matrículas en los colegios privados resultaba oneroso y difícil de cubrir. No obstante, se tenía la convicción de que este esfuerzo -que podría rayar en el sacrificio- era indispensable para la mejor formación, sobre todo de las hijas.

En cuanto al apoyo para orientar a los hijos/as en la elaboración de los deberes o tareas, en una de las familias representó un esfuerzo salvable, gracias a la escolaridad de la abuela. Pero en otra, la abuela no concluyó sus estudios de educación básica (primaria) por lo que el papel de orientador lo asumió el padre, aunque era limitado el tiempo que podía dedicar para asesorar a sus hijos/as.

Sin importar el país o la generación, las mujeres expresan comportamientos emotivos, de orgullo, admiración y satisfacción por haber logrado que sus hijos/as alcanzaran una escolaridad superior a la que ellas obtuvieron en su tiempo. A continuación se presentan los relatos de las triadas colombianas:

Abuela:

Me encantaba ir a la escuela, me gustaba mucho estudiar. Nunca tenía pereza de ir. La función [es muy] importante, la educación empieza en la casa, pero para complementarla, para ser mejores personas, [y] saberse manejar mejor en la sociedad. ¡No! la ignorancia es muy triste. Porque uno, sabiendo, se puede relacionar mejor con la gente, para muchas cosas le sirve a uno [la educación], no es ignorante, es muy importante para uno aprender, uno sin saber nada no puede entender una conversación, muchas veces no puede estar con personas, como que no se atreve uno. [...] Claro, si no hubiera estudiado no habría podido trabajar (Abuela-Col.). 


\section{Madre:}

[Estudiar] para poder tener un empleo digno, para ser alguien en la vida, era lo que le decían a uno, [...] y para también a futuro formar familia. Porque eso le daba a uno la posibilidad de asegurar el sustento de la familia.

[A través de la escuela] se aprende a compartir, a convivir, a reconocer a los otros desde la diferencia, se aprenden conceptos académicos, científicos, se tienen experiencias de poder demostrar hipótesis que de pronto uno tiene planteadas y al momento de ir a la escuela las puede comprobar, sea que son verdad, que no son verdad, pero te da esa posibilidad.

Pues el fin último de la escuela es permitirle a las personas que aprendan a vivir en comunidad, independientemente si aprende matemáticas, inglés, francés, español, alguna área científica como tal, no, eso no influye en nada en la vida de una persona, pero si no aprende a vivir en comunidad, si no aprende a aceptar al otro, si no aprende cuándo una persona está apta para sostener una conversación, cuándo una persona puede demostrar valores como la honestidad, la humildad, la perseverancia, la responsabilidad y la disciplina, independiente de lo que uno aprenda como conceptos, si uno no va a la escuela no tiene esa posibilidad de vivir. Entonces, el fin último de la educación es aprender a vivir en comunidad (Madre-Col.).

Nieta:

[Estudiar] te hace mejor persona, abre tu mente, tienes de qué hablar con otras personas, no te quedas en medio de la ignorancia [...] siempre me ha gustado estudiar porque vas a ser alguien, vas a tener tu mente abierta, porque no vas a ser ignorante.

[La escuela] Forma seres humanos que sean respetuosos con la sociedad (Nieta-Col.).

\section{COMPARACIÓN GENERACIONAL: ESCUELA PRIVADA VS. ESCUELA PÚBLICA}

Un aspecto destacable es la importancia y el significado que cinco de las entrevistadas le otorgan a la posibilidad que tuvieron de asistir a colegios privados confesionales o religiosos. En el discurso sobresale la ventaja de que las mujeres puedan acudir a este tipo de establecimientos, porque no solo 
les permite obtener conocimientos sino que sobre todo les proporciona seguridad, la adopción de buenas costumbres, el fomento de la disciplina y una formación en valores, en particular propios de la religión católica.

Llama la atención en estos casos estudiados que quienes tienen la última palabra para decidir a qué colegio envían a sus hijos/as son las madres, no importa el costo ni la opinión del esposo. En la elección del colegio no interviene únicamente el costo económico, sino también las diferentes nociones sobre la educación. En Colombia se cree que las mujeres deben educarse en colegios de monjas o incluso en aquellos donde estudien exclusivamente niñas. En México, hace algunos años se pensaba que los hombres no estudiaban en colegios religiosos porque podrían volverse amanerados; en los salones de clase de este tipo de colegios había pocos varones.

Las mujeres representan un papel central en la toma de decisiones al interior de sus familias, sobre todo las que están relacionadas con la formación de los hijos/as. A menudo son, si no las iniciadoras de los proyectos, sí sus gestoras y realizadoras. En términos generales, se aprecia una notable convergencia entre la importancia que en las tres generaciones ha tenido la educación escolarizada, el compromiso asumido por las mujeres en el proceso educativo de sus hijos/as, y particularmente las expectativas, significados y visiones respecto al tipo de colegio donde deben estudiar. De acuerdo con la triada mexicana:

Abuela:

[...] y ya después con [Liliana y Carlota] ya las pude meter ahí [colegio religioso], en el caso de mi hijo el varón, no se me hizo muy duro mandarlo a la escuela de gobierno (pública), sino que a las niñas era mejor mandarlas [al colegio privado] (Abuela-Méx.).

Madre:

Pues muy importantes [los valores], pues no robar, eso desde tu casa, ¿no?, que no agarres lo que no es tuyo, pues friegas que te ponían. [...] En la clase de valores, que ahora es valores, era catecismo, nos daban una hora que "se soplaba" uno con las religiosas, y nos decían qué cosas eran buenas, qué cosas eran malas; lo cual es excelente porque nos decían que si nosotros hacíamos algo 
mal nos íbamos a ir al infierno; bueno, no sabemos si existe o no, pero de algo estoy segura, que yo creo que fue muy bueno porque pues no salió uno peor, o sea, estuvo bueno.

[...] yo siento que sí son muy diferentes, en escuelas públicas a veces te dejan llegar a la hora que tú quieras, van a veces los que quieren. En las privadas hay como que una disciplina muy marcada, [...] no puedes llegar dos, tres minutos [tarde], porque ya te están cerrando la puerta; o tienes que pararte así, incomoda en el momento. Pero ahora, que yo lo veo, me ha servido mucho a mí.

La directora que nos daba clases de personalidad nos decía cómo teníamos que sentarnos a la mesa, cómo tienes que agarrar un cubierto, eso me lo enseñó mi papá, pero yo la recuerdo mucho a ella, decía: "Es que esto también es educación, cómo una señorita se tiene que sentar con las piernas cerradas, cuando traigan falda de lado, así [mueve las piernas]". Esa educación me ha dado más conocimiento, y yo creo que en una escuela pública no hubiera logrado aprender esas cosas.

Él (Gildardo) nunca quería que estudiaran en escuela particular, eso era algo que a él le podía mucho, [...] no estábamos en el mismo canal y no estábamos sintonizados en ese aspecto, porque él siempre pensaba que por ir en esa escuela [Isidro] se iba a volver amanerado o algo así, decía siempre lo mismo (Madre-Méx.).

Nieta:

Sí, yo fui a un colegio de monjas por así decirlo, era colegio católico, entonces sí, la disciplina siempre ha sido demasiada en ese colegio. Muy, muy estrictos, sobre todo con la puntualidad, [...] tenía uno que entrar a las ocho en punto, ni un minuto más porque cerraban la escuela y pues se me hacía luego tarde y ya no entraba. Entonces sí, muy disciplinados y es lo que me gusta del colegio, la verdad.

Bueno, mi mamá estudió ahí, [...], en ese entonces, pues por la opinión de varias personas, [era] el mejor, y más que nada por el cariño a la escuela, porque tenía buen nivel educativo, [por] las instalaciones. Había [otros colegios] pero [...] como mi mamá fue ahí desde chica, ese fue el que le gustó para que asistiéramos nosotros.

Más que nada mi mamá, porque mi papá no estaba muy de acuerdo en pagar una colegiatura (matrícula), pero más que nada la que se empeñó en que fuéramos a colegio privado era mi mamá. Sí, pues quería otro ambiente [...], 
otro tipo de amistades y tiene muy buen nivel la escuela. Pero más que nada fue mi mamá la que se empeñó, pero si por mi papá hubiera sido [hubiéramos ido a] un colegio público. Él siempre decía que "el que es perico donde quiere es verde", era su lema.

Me quería meter [habla del papá] en una escuela pública, pero [...] ¡no, era la desgracia!, porque estás acostumbrada a estar en una escuela diferente a una pública, o sea, otro tipo de gente, la escuela bonita, o sea, son como dos mundos la verdad.

Sí, al menos en México y por lo menos en primaria, secundaria [...] en mi opinión sí me gusta que vayan a un colegio, yo creo que el número uno es la disciplina, porque si no eres disciplinado no vas a hacer nada. Ahí en la escuela te piden que lleves el calzado, todo, el uniforme impecable, tu pelo, el moño que debe corresponder al día de la semana, que llegues a tal hora, a veces se me hace tarde. No me parece mucho cuando ya no te dejan pasar, pero está bien, son más estrictos que en una pública. En una pública luego veo que las niñas pues llevan unas chamarritas de otro tipo, cada quien lleva una falda de uno, falda de otro, el zapato de un tipo, hasta no es blanco, entonces no tienen mucha disciplina. Cuando la directora dice no hay clases, no hay clases, no son tan estrictos como acá (Nieta-Méx.).

En Colombia la educación religiosa católica ha tenido un gran peso e importancia, en especial desde la llamada Regeneración de 1886 hasta nuestros días (debido a que tardíamente se decretó la libertad de cultos). Según Rey (2015: 243), el proyecto político de la Regeneración "representó una transformación radical de la instrucción pública en el país, lo cual se manifestó en especial por la entrega de la formación a la Iglesia católica". La educación tenía que ser congruente con los ideales de la civilización católica, donde la moralidad debía jugar un papel predominante en la formación de los ciudadanos.

A pesar de los intentos que hubo durante los siglos XIX y xx por limitar la influencia de la religión en la educación, en Antioquia no se ratificaban los acuerdos. "Para muchos conservadores, un programa educativo que daba la espalda a la religión conduciría inexorablemente al caos y la corrupción" (Londoño, 2004: 219). Se creía que la cohesión y estabilidad social solo podía darla la Iglesia.

No fue hasta 1991 cuando se proclamó por primera vez en el país la libertad religiosa (Echeverri, 2012: 12). En el artículo 68, inciso 4, de la Carta 
política se señala que "las instituciones estatales no pueden ser confesionales mientras esa condición es posible para las privadas" (2012: 128). Algo que debe resaltarse es que la Ley General de Educación vigente se contradice con el artículo 68 en los siguientes términos:

El artículo 23 de la Ley General de Educación hace obligatoria la educación religiosa para todas las instituciones educativas tanto estatales como privadas. Una orientación ratificada por las resoluciones y directivas del Ministerio de Educación Nacional de junio 5 de 1996 y febrero de 2004 y el Decreto 4500 de diciembre de 2006, que señala a la formación religiosa como una área obligatoria y fundamental dentro del currículo (Echeverri, 2012: 128).

Esto ha dado pie a varios debates. Por un lado, que el Estado permita que tanto en las instituciones privadas como en las públicas se imparta la religión católica porque es la que registra la mayor cantidad de feligreses en el país. Por el otro, que haya instituciones, minoritarias aún, que imparten cualquier otro culto. De acuerdo con las triadas colombianas:

Abuela:

Las matriculé en ese colegio de religiosas porque era el mejor que había en lo moral, en lo académico y en el comportamiento. Era solo para mujeres. Vivíamos en un lugar chico y no había otro colegio privado. Yo estudié ahí y me pareció muy buen colegio. Uno les da estudio a los hijos para que se preparen para enfrentar la vida, uno quiere para ellos lo mejor. Sobre todo que sean responsables en todo sentido (Abuela-Col.).

Madre:

Mi mamá fue educada en colegio de religiosas, y de todas maneras en esa época la religión católica ejercía mucha influencia en la educación y en el Gobierno, pues o se practicaba la educación religiosa, o se practicaba; o sea, ahí no había opción de algo diferente. Y de todas maneras pues mi mamá tenía la experiencia de estudiar en colegios religiosos, tenía su experiencia de vida, entonces quería que sus hijas también la tuvieran.

[...] ahora se preocupa uno porque los hijos vayan a un colegio donde básicamente le den esa parte de la moral y la ética. En esa época se les delegaba 
toda esa responsabilidad a las religiosas y el colegio que había para mujeres de religiosas era ese, y a ese nos entraron a estudiar. [...] Responsabilidad, disciplina, nos metieron mucha religión, el respeto, las buenas obras, la honestidad.

[...] busqué que [el colegio] fuera femenino para que se educaran en esa parte de la femineidad, de la delicadeza, de los valores; se tiene la idea de que cuando se comparte con el género masculino, hay como muchas situaciones de aprendizaje que no favorecen, por de hecho las mujeres y los hombres aprendemos diferente [...]. Siempre he sido partidaria de la educación diferenciada, en un momento [...] compartir ciertos espacios, ciertas situaciones, pero en sí la formación me parece que es interesante que sea diferenciada. Las mujeres aprenden de una manera, los hombres de otra, el proceso evolutivo de las mujeres es uno, el de los hombres es otro. Entonces es bueno mantener eso, incluso para mantener eso de la pureza del género, [...], por eso les escogí ese colegio (Madre-Col.).

Nieta:

La escuela era privada, un colegio religioso, era solo de niñas porque a mi mamá no le gustaba que estudiara en una escuela mixta, porque cuando estamos con niños nos hacíamos como ellos, adoptábamos muchos gestos o actitudes de niños. Mi mamá escogió lo que era mejor para nosotras, mi papá no estaba de acuerdo porque decía que la [escuela] pública era más barata y que no podían darnos todo tan fácil.

La privada era diferente a la pública, en esta uno podía encontrar personas de bajos recursos. El costo es más económico y podían ir personas de bajos recursos. Entonces iban a ir personas que tuvieran vicios (Nieta-Col.).

En el caso particular de estas triadas, se observa que sus razones para elegir o preferir un colegio privado religioso en lugar de uno público son diversas. Hay un fuerte incentivo por reforzar la educación moral y religiosa con la que tiene afinidad la familia; según ellas el ambiente es de "mejor cuidado y atención" hacia las niñas, que en otro colegio no se garantiza. Todo esto respaldado porque en los colegios privados hay un proceso de selección que impide que cualquiera ingrese o se mantenga dentro de la institución. Buscan no solo una educación diferenciada para niños y niñas, sino también espacios selectivos de socialización y en general aprendizajes de género. 
En los dos países existe el debate sobre lo que cada institución ofrece. Sin embargo, esto no les interesa a las familias, a ellas les importa que sus hijos/as egresen en el colegio "más reconocido en su localidad", aquel que, independientemente de la fuerte erogación económica de los padres, cuenta con instalaciones confortables, equipadas, pocos estudiantes por aula, refuerzan los valores aprendidos en casa y por la religión que allí se enseña ${ }^{4}$.

\section{REFLEXIONES FINALES}

En esta investigación se asume que la escuela es una de las instituciones sociales más importantes en las sociedades occidentales, porque prepara a los niños, adolescentes y jóvenes para el mundo de los adultos y del trabajo. En la institución educativa los seres humanos alcanzan y cualifican tal dimensión, reciben en un relevo generacional la estafeta, conformada por conocimientos y saberes acumulados, renovados y transformados, que harán posible la permanencia de la sociedad en un contexto cambiante, con un acervo creado durante el tiempo y que requiere ser transmitido, recuperado y reelaborado generacionalmente.

La escuela es relevante por ser el espacio socialmente diseñado y legitimado para la sociabilización de niños, jóvenes y adultos con sus pares. Es similar a un laboratorio que prepara para aprender a vivir en la sociedad a la que se pertenece; reconocer y asimilar reglas, valores, disciplinas, hábitos, normas de comportamiento y de convivencia. Construye visiones de futuro, formas de ver, entender y comprender el mundo y la vida; prepara para seguir la luz de las utopías que cada sociedad crea o reconoce como su faro orientador. Pero a pesar de su reconocimiento y legitimidad social también imprime y reproduce dinámicas de desigualdad, relaciones de poder y una concepción meritocrática de la vida social. Lo anterior sin dejar de lado que, para quienes pasan por sus aulas, resulta una fuente inagotable de experiencias y recuerdos que dejan una marca indeleble. Es un espacio de vivencias, y emociones, donde suelen hacerse los mejores amigos.

\footnotetext{
${ }^{4}$ No deja de ser paradójico para el caso mexicano, donde la educación es constitucionalmente laica.
} 
Analizar relatos de vida permitió ver la percepción de las abuelas, madres y nietas, tres generaciones que perciben la escuela y observan la educación desde contextos geográficos e históricos distintos pero con claves interpretativas similares. Para ellas no hay una desarticulación entre escuela y familia sino un fuerte vínculo. Tampoco hay crisis; como madres han cumplido con la parte que les corresponde. Las triadas valoran y le atribuyen gran importancia a la escuela desde sus expectativas y significados, como proyección de futuro, bienestar, oportunidad de tener un buen empleo, pero también como posibilidad de conservar ciertos valores, creencias y hábitos. Algunos muy conservadores y estructurantes. Por un lado, las mujeres - sin importar la generación-impulsan a sus hijas a formarse, a estudiar lo que prefieran y hasta donde quieran, pero las envían a colegios confesionales católicos sin considerar la opinión de los esposos. Instituciones donde les enseñen a comportarse de manera diferente a los hombres, a ser delicadas, a no dejar que las manoseen, a aprender a "sentarse con las piernas cerradas" y que solo hasta cierta edad puedan convivir con los varones, porque de lo contrario "se pueden volver como ellos". Colegios privados donde aprenden a convivir con los iguales según: sexo, clase e ideología.

Se encuentran posturas donde podemos ver rupturas y cambios, pero otras donde aparecen discursos muy conservadores, contradictorios y excluyentes. Las mujeres aspiran a que sus hijas sean diferentes a ellas, con mayores posibilidades de desarrollo y bienestar económico; que sean autónomas, "que no se dejen del marido", pero las envían a los colegios religiosos donde ellas estudiaron o bien a instituciones donde les refuercen los aprendizajes familiares, reproduciendo esquemas de comportamiento intergeneracional.

Las narrativas actuales de las mujeres que no pudieron o no quisieron concluir sus estudios evidencian cómo las personas recuperan y cambian sus perspectivas en torno a la escolaridad de una generación a otra. La educación escolarizada, sin importar el país o la generación, es valorada positivamente. Es una institución social de gran importancia encargada de formar en el plano físico, moral e intelectual.

En general, se observó que las mujeres asumen el compromiso moral y económico en el proceso educativo de sus hijos. Llama la atención que las colombianas llegan a contraer fuertes endeudamientos con tal de conseguir que 
sus hijos estudien en determinadas instituciones educativas, el prestigio de los colegios o universidades privadas pesa mucho en la toma de decisiones.

Ambas triadas consideran que la educación escolarizada es importante para que los hijos/as puedan acceder a un buen empleo, pero como se había señalado hay más argumentos: poder tomar mejores decisiones, saber hablar, poder desarrollarse en diferentes espacios geográficos y culturales, seguir aprendiendo, levantar y formar una familia, ser respetado/a, poseer conocimientos y valores, entre otros. Estas manifestaciones son similares a las que encontró Saucedo, y que le permiten afirmar que los individuos valoran la escuela mediados por su cultura, sus experiencias particulares de vida e incluso por el momento histórico:

Las personas continuamente están reescribiendo su vida y por tanto el valor de la escolaridad. [...] En un país como el nuestro [México], con fuertes restricciones económicas y del mercado laboral, muchas personas seguirán aceptando y manejando un valor general de la escuela como medio para el empleo. Sin embargo, la escuela seguirá siendo valorada desde la subjetividad de los individuos a partir de sus experiencias concretas (Saucedo, 2003: 96).

Se hallaron más similitudes que diferencias entre las dos triadas. Destaca la relevancia e importancia que le confieren al hecho de haber estudiado en colegios privados católicos, donde adquirieron conocimientos, valores, hábitos, creencias y la disciplina que han conservado y transmitido de una generación a otra. En los relatos también aparecen sentimientos positivos respecto a los logros educativos personales o el poder contribuir para que otros integrantes de la familia estudiaran o estudien. Emociones tales como orgullo, satisfacción, alegría, interés, gusto y entusiasmo son las más recurrentes. Aunque las mujeres que no concluyeron sus estudios manifiestan arrepentimiento y frustración por no haberlo logrado.

\section{BiBLIOGRAFÍA}

Bernasconi, O. (2011). Aproximación narrativa al estudio de fenómenos sociales: principales líneas de desarrollo. Acta Sociológica, 56, 9-36. 
Bertaux, D. (1999). El enfoque biográfico: su validez metodológica, sus potencialidades. Proposiciones, 29, 1-23.

Caballero, M. (2014). Tres tiempos: cambios sociales en tres generaciones de mujeres en México. México: UAEM/MA Editores.

CARBonell, J. (1996). La escuela: entre la utopía y la realidad. Barcelona: Octaedro.

Donati, P. (1999). Familias y generaciones. Revista Desacatos, 2, 27-49.

ECHEVERRI, A. (2012). Libertad religiosa y educación en Colombia: Ni intocables ni míticas. Revista Cientifica Guillermo de Ockham, 10(1), 123-134. Recuperado de: http://www.redalyc.org/articulo.oa?id=105324310010. Consulta: 15 de febrero de 2018.

FingermanN, H. (2011). Importancia de la escuela. Recuperado de: http:// educacion.laguia2000.com/general/importancia-de-la-escuela \#ixzz4daY4boa5. Consulta: 10 de agosto de 2017.

Gvirtz, S.; Grinberg, S. y Abregú, V. (2012). La educación ayer, hoy y mañana. Buenos Aires: Editorial AIQUE.

Londoño, P. (2004). Religión, cultura y sociedad en Colombia. Medellín y Antioquia 1850-1930. Bogotá: FCE.

MarTín, M. (2009). La teoría de las generaciones de Ortega y Gasset: una lectura del siglo XXI. Revista Tiempo y Espacio, 17(20). Recuperado de: http://www.ubiobio.cl/miweb/webfile/media/222/Tiempo/2008/07\% 20Marco\%20Martin\%20articulo\%20pag\%2098-110.pdf. Consulta: 15 de agosto de 2017.

PÉrez, A. (2000). La cultura escolar en la sociedad neoliberal. Madrid: Morata.

Rey, D. (2015). La Educación de las mujeres en Colombia a finales del siglo XIX: Santander y el Proyecto Educativo de la Regeneración. Revista Historia de la educación latinoamericana, 17(24), 243-258. Recuperado de: http://www.scielo.org.co/pdf/rhel/v17n24/v17n24a12.pdf. Consulta: 15 de octubre de 2018.

SAuCEDo, C. (2003). Entre lo colectivo y lo individual: la experiencia de la escuela a través de relatos de vida. Nueva Antropología, XIX(62), 77-98. Recuperado de: http://www.redalyc.org/articulo.oa?id=15906205. Consulta: 5 de enero de 2018.

Stake, R. (2010). Investigación con estudios de casos. Madrid: Morata. 
VASEn, J. (2008). Las certezas perdidas. Padres y maestros ante los desafios del presente. Buenos Aires: Paidós.

VÁzquez, G.; Sarramona, J. y Touriñán, J. M. (2009). La escuela, en crisis. En J. Peña y C. Fernández (coords.), La escuela en crisis (pp. 17-78). Barcelona: Octaedro. 